Dr. Gonzalo Sarasqueta

Universidad Católica Argentina

@ gonzalo_sarasqueta@uca.edu.ar iD 0000-0001-6472-8672
- Recibido / Received 10 de octubre de 2020

- Aceptado / Acepted 25 de octubre de 2020

- Páginas / Pages De la 73 a la 84

- ISSN: 1885-365X

\title{
Técnicas de la comunicación política ante la era de la infoxicación y la interrupción: del storytelling al storydoing
}

\section{Techniques of political communication in the era of infoxication and interruption: from storytelling to storydoing}

\section{RESUMEN:}

Ante un contexto saturado de información, donde la atención es un bien escaso, la ciudadanía le reclama acciones más que discursos a sus líderes. Esta demanda social impulsa un cambio crucial en la comunicación política actual: el paso del storytelling (relatar con palabras) al storydoing (relatar con hechos). Presidentes, gobernadoras y alcaldes de todo el mundo comienzan a utilizar esta técnica narrativa que, a través del registro visual, dinamiza voluntades y, a su vez, les proporciona credibilidad. El objetivo del presente trabajo es brindarle un marco teórico - conceptualización, requisitos, propiedades y usos - a esta herramienta comunicacional emergente denominada storydoing.

\section{PALABRAS CLAVE:}

Storydoing; Storytelling; Credibilidad; Infoxicación; Cultura hípervisual; Hechos.

\section{ABSTRACT:}

Faced with a context saturated with information, where attention is a scarce commodity, citizens demand actions more than speeches from their leaders. This social demand drives a crucial change in current political communication: the shift from storytelling (telling with words) to storydoing (tellin with facts). Presidents, governors and mayors from all over the world are beginning to use this narrative technique that, through visual record, energizes wills and, in turn, provides them with credibility. The objective of this work is to give a theoretical framework - conceptualization, requirements, properties and uses - to this emerging communicational tool called storydoing.

\section{KEY WORDS:}

Storydoing; Storytelling; Credibility; Infoxication; Hypervisual culture; Facts. 


\section{Introducción}

El Covid-19 cristalizó una nueva era comunicacional. El incremento de la modalidad virtual en las esferas del ocio y del trabajo, el avance del capitalismo cognitivo sobre el capitalismo industrial y, en especial, la saturación de contenidos son los principales fenómenos que caracterizan a esta época. La pandemia aceleró todos estos procesos y los cambios que iban a tardar años en desarrollarse, se comprimieron en apenas unos meses.

En un contexto donde la información correcta - el uso del tapabocas, el lavado de manos o el distanciamiento social - puede salvar la vida de millones de personas, la híper circulación de contenidos puede convertirse en un inconveniente. La comunicación de riesgo confeccionada por los gobiernos y el campo de la medicina se mezcla con enunciados sin respaldo científico y fake news. En el medio de esta confusión, queda el ciudadano prosumidor que, sin corroborar la rigurosidad ni la fuente, divulga el mensaje. A este problema comunicacional de escala global la Organización Mundial de la Salud (OMS) lo denominó «infodemia».

Esta infoxicación supone un desafío para los liderazgos políticos actuales. Durante la crisis del Covid-19, los gobernantes han tenido que desplegar una comunicación permanente sobre su gestión y, al mismo tiempo, generar hechos contundentes que capten la atención social y les permitan distinguirse del ruido informativo. A lo largo y ancho del planeta, se construyeron diferentes narrativas para enfrentar al coronavirus. Por un lado, se establecieron aquellas piezas que estaban esbozadas íntegramente con palabras, el llamado storytelling. Aquí se encuadraron los casos de Donald Trump, Jair Bolsonnaro, Víktor Orban, Andrés Manuel López Obrador, Rodrigo Duterte y, al inicio, Boris Johnson. En paralelo, irrumpió otro estilo que buscó relatar a través de acciones concretas y al que reconoceremos como storydoing. Entre estos mandatarios podemos mencionar a Justin Trudeau, Jacinda Ardern, Luis Lacalle Pou, Leo Varadkar, Erna Solberg, Tsai Ing-Wen, Angela Merkel, Katrín Jakobsdóttir y Sanna Marin.

Teniendo en cuenta esta última categoría, este trabajo aspira a brindarle un marco teórico al storydoing político. Para cumplir dicha meta se establecerán los siguientes objetivos secundarios: (I) realizar una descripción del contexto comunicacional actual; (II) conceptualizar a esta técnica narrativa; (III) determinar sus requisitos y propiedades; y, por último, (IV) elaborar una tipología que refleje sus diferentes usos. Para cerrar se ofrecerán unas breves conclusiones y unos interrogantes que quedan abiertos para futuras investigaciones.

\section{Contexto: la consolidación de la ciberdemocracia}

Internet fue la bisagra entre la comunicación y la autocomunicación de masas (Castells, 2011). La red permitió el ascenso del ciudadano prosumidor, un sujeto que consume y crea contenidos (Ritzer and Jurgenson 2010). El modelo vertical, unilateral y asimétrico, donde un periodista de Cadena Ser hablaba a una multitud de oyentes pasivos, es reemplazado por un sistema más horizontal, relacional y simétrico, donde esos oyentes tienen la posibilidad de convertirse en emisores activos que amplifican, cuestionan o resignifican los postulados del periodista profesional a través de un tweet o un posteo en Facebook. Esta nueva lógica 
repercute directamente en la opinión pública, que se democratiza incorporando una mayor cantidad de voces, pero a su vez pierde nitidez y consistencia.

Cada minuto, en todo el mundo, millones de personas crean mensajes. Esto quiere decir que a las noticias que propagan los mass-media, hay que añadirle todo el material que difunde la ciudadanía a través de sus plataformas digitales. El resultado es un ecosistema comunicacional hipertrofiado, cargado de dispositivos, datos y subjetividades. La literatura académica y el periodismo han utilizado diferentes términos para sintetizar a este proceso comunicacional: «cacofonía» (Dahlgren, 2005), «contexto colapsado» (Boyd, 2008), «ruido permanente» (Gutiérrez Rubí, 2009), «infoxicación» (Chamorro-Premuzic, 2014) y «obesidad mental» (Naskar, 2019).

Asimismo, esta sobreoferta de información, sumada a la aceleración de los flujos comunicacionales, ha alterado drásticamente el acceso del ciudadano a la opinión pública. Mientras una persona lee Clarín o The Guardian, por ejemplo, le puede aparecer una notificación de Linkedin y, en simultáneo, llegarle una alerta de Whatsapp. Esta sincronía dificulta la concentración y promueve la mudanza constante de una aplicación a otra. Debido a esta volatilidad, el columnista del The New York Times, Thomas Friedman (2006), advirtió que estábamos pasando de la «Era de la información» a la «Era de la interrupción».

En la «Era de la interrupción», la atención es un bien escaso. Hoy en día, se estima que "cuatro segundos es el tiempo de nuestra paciencia cognitiva para seguir leyendo un artículo de un sitio web» (Gutiérrez Rubí, 2019: 78). La administración de este capital exiguo ha llegado a tal punto que autores como Michael Goldhaber (1997) y Richard Lanham (2006) se refieren a la «economía de la atención». Un concepto que sintetiza la contradicción que caracteriza al ciberespacio: mientras la información es infinita, la atención es finita. Este dilema moldea al mercado digital actual, donde las grandes corporaciones dependen de dos recursos: datos y atención. Los primeros sirven para delinear y microsegmentar los contenidos y, de esta manera, atraer la segunda, es decir, el interés del cibernauta.

El escueto margen de tiempo que otorga el navegador a cada posteo o noticia ha impactado en la gramática de la Web. La síntesis se transformó en un imperativo. Frente a una atención fugaz, los textos deben ser breves. El ejemplo más claro de esta economía discursiva es la red social Twitter, que está regida por la administración de los caracteres, no de las palabras. En poco espacio hay que comunicar mucho. Tomando como ejemplo el caso de Donald Trump, Christian Salmon (2019) acuñó el término militar «conmoción y temor» para representar esta modalidad discursiva que prioriza el titular sobre el desarrollo, lo táctico sobre lo estratégico y la reacción sobre la reflexión.

La imagen es otro atajo cognitivo que se emplea para superar a la atención efímera. Esto se debe a que el registro visual posee la capacidad de concentrar una elevada cantidad de significado en un marco temporal acotado. Como sostiene el investigador inglés Darren Lilleker (2019), en una época donde el ciudadano no está dispuesto a hacer grandes esfuerzos para informarse, las imágenes son requeridas porque ofrecen respuestas simples y categóricas de lo que está sucediendo. Messaris (2019) agrega que el avance del formato visual responde a la multiplicación de los teléfonos inteligentes con cámaras, las aplicaciones de edición y las fuentes brindadas por internet que facilitan el acceso a las imágenes. En esta época de la fotografía ubicua (Hand, 2012), incluimos los diferentes recursos visuales que ofrecen las redes sociales: emojis, stickers, memes y GIFs. Dichas piezas, que también 
funcionan como heurísticos cognitivos, están ocasionando una metamorfosis profunda en el lenguaje político. Las grandes narrativas, con sus simbologías maximalistas, fundamentos ideológicos y anclajes colectivos, son reemplazadas por microrrelatos personalizados, estructurados mediante una estética cotidiana, distendida y horizontal, que apunta a conectar mediante las emociones con el individuo posmoderno (Gerodimos, 2019).

Las imágenes cobran mayor importancia por el ascenso de un ciudadano que destaca por su avaricia cognitiva (Popkin, 1994). Esto significa que, ante el «tsunami» de información que reciben, las personas optan por realizar un mínimo esfuerzo mental para tomar una decisión política o forjar una opinión sobra tal líder. Entre la ruta central (procesamiento meticuloso de la información) y la ruta periférica (procesamiento superficial de la información) ${ }^{1}$, prima esta última (Perloff, 2018). Los investigadores Lilleker y Liefbroer lo explican así:

En este entorno de comunicación no regulado e incontrolable, los hechos son permeables, todas las verdades son discutibles, por lo que el ciudadano debe recurrir a atajos y heurísticas para determinar en qué medida un reclamo es más cierto que otro. La conclusión lógica es que cuando a un ciudadano se le presentan argumentos muy contrastantes, es cada vez más probable que intente hacer evaluaciones rápidas basadas en los instintos (2018: 353$)$.

Por último, señalar la trascendencia que tienen las emociones en la comunicación actual. Las redes sociales han difuminado las fronteras entre los espacios público y privado. La intimidad es el insumo principal de aplicaciones como Instagram, Facebook o Tik Tok. Diputadas, alcaldes, gobernadoras y presidentes aceptan mostrar su privacidad para llegar a lo que Papacharissi denomina «públicos afectivos» (2016). Estos seguidores no se guían por las políticas públicas o los argumentos de los líderes, sino que se movilizan por sentimientos asociados a los atributos personales - no ideológicos - de las figuras públicas. Así, los políticos efectúan un uso estratégico de sus familias, cuerpos, gustos y consumos. Es el paso de la opinión pública a la emoción pública (Salmon, 2008).

En síntesis, frente a este ciudadano cognitivamente mezquino, la comunicación política empieza a modificar su praxis en tres sentidos: intensificación de la segmentación y del delivery de mensajes (el llamado «big data»); los contenidos se diseñan a través del formato visual y de la economía discursiva; y, como veremos en el próximo inciso, las narraciones personales son el núcleo de las piezas comunicacionales.

\section{Cambio de paradigma: del storytelling al storydoing}

Si bien en las últimas dos décadas ha crecido notoriamente el interés por el storytelling, esta herramienta comunicacional existe desde la Antigua Grecia. La búsqueda por movilizar el sentido social a través de narrativas épicas fue un recurso común en los orígenes de la cultura

1/ El psicólogo Daniel Kahneman utiliza las categorías «sistema de esfuerzo» y «sistema automático». El primero consiste en un trabajo cognitivo lento, elaborado y sustentado en evidencia empírica; el segundo, en cambio, es involuntario, rápido y está dominado por las emociones. 
occidental. Hace miles de años, batallas, soldados y líderes se transformaban en hazañas, héroes y mitos que funcionaban como arquetipos a los que debían aspirar los ciudadanos comunes. El teórico español Enrique Gil Calvo argumenta al respecto:

\begin{abstract}
Ahora bien, al margen de esta reciente moda posmoderna las stories o microrrelatos electorales del «infoentretenimiento", lo cierto que es que la narratividad siempre ha presidido el ejercicio de la comunicación política, empezando desde los propios griegos. Con lo cual regresamos al mundo de la democracia ateniense analizada por Aristóteles, pues esta búsqueda de la relación emocional con los electores, que plantea el marketing narrativo, es la misma búsqueda del ethos, entendido como relación emocional con los oyentes, que planteó el estagirita como clave de la retórica discusiva (2018: 123).
\end{abstract}

Esa inyección de ficción que se le aplicaba a hechos corrientes era fundamental para convertirlos en miméticos, en acciones que las generaciones futuras debían emular. De esta manera, el storytelling que construían los narradores era más relevante que los sucesos mismos. Selección deliberada, simplificación, descontextualización, invención, omisión y exageración eran prácticas frecuentes entre los storytellers. La verosimilitud reemplazaba a la veracidad. Era suficiente con que la historia exhibiera solo algunos aspectos reales para alcanzar el status de creible. Esto se debe especialmente a que «la mente humana es un procesador de historias, no un procesador lógico» (Haidt, 2019: 404). A pesar de ser reconstrucciones post hoc, el storytelling determina nuestro estado de ánimo. Las personas que enlazan traumas o situaciones dolorosas con éxitos o logros posteriores son más alegres que las que no tienen estos relatos de resiliencia (McAdams, 2006). Además, estudios científicos en Estados Unidos demuestran que las personas cuando escuchan historias liberan oxitocina, la hormona de la empatía y el afecto (Brooks, 2019).

Los investigadores argentinos Orlando D’Adamo y Virginia García Beaudoux (2016) entienden el storytelling como una técnica comunicacional que se emplea para la construcción de relatos políticos. Los principales elementos del storytelling son los siguientes: un arco tripartito (introducción-nudo-desenlace) que ordena la historia y le aporta coherencia; un protagonista que encarna valores positivos y sirve de ejemplo social; un desafío o un enemigo que le proporciona suspenso y una moraleja que deja una enseñanza a la audiencia. En un contexto marcado por la saturación de información, la economía discursiva, la cultura hípervisual y la crisis de representación política, el poder persuasivo del storytelling disminuye. La sociedad demanda contundencia, hechos e imagenes. Exige que las narraciones de sus líderes sean a través de acciones, no palabras. Ya no se trata de lo que dicen Pedro Sánchez y Jacinda Ardern, sino de lo que hacen. Este es el salto epistemológico del storytelling al storydoing que está dando la comunicación política.

A pesar de que ciertos investigadores y consultores - especialmente del ámbito corporativo- alegan que el storytelling se ha vuelto una técnica superflua (Montague, 2018; Weber, 2019) o que incluso «ha muerto» (Vallance, 2016), es imperioso aclarar que el texto continúa siendo preponderante y determinante en la comunicación política. La novedad es que se le añade la comunicación de la acción. El objetivo es lograr que haya una coherencia entre el decir y el hacer. La sinergia entre ambos componentes, palabra e imagen, creará una narrativa robusta (Luntz, 2011). Como sostiene Paul Martin Lester: «Los mensajes más poderosos, 
significativos y culturalmente importantes son aquellos que combinan palabras e imágenes por igual y respetuosamente» (Lester en Gurri, Denny y Harms, 2010: 102).

Al ser un término reciente, no abundan las conceptualizaciones sobre el storydoing. Desde la comunicación corporativa, Baraybar Fernández y Luque de Marcos lo han definido de la siguiente manera:
...como una propuesta para generar contenidos en el proceso de construcción y gestión de marcas, fundamentada en crear productos, servicios y experiencias que sean percibidas como un valor tangible por lasociedad. Surge como alternativa a la pérdida de eficacia en el contexto actual de las fórmulas anteriores e invita a las organizaciones a reflexionar sobre su sentido y su aportación a la colectividad; a revisar su historia, sus productos, su manera de comunicar y, quizás lo más relevante, precisar su propósito (2018: 452).

Teniendo en cuenta que el presente trabajo se enmarca en el campo de la comunicación política, definiremos al storydoing como una técnica narrativa que, a través de la visualización de acciones o experiencias, moviliza el sentido social y, al mismo tiempo, incrementa la credibilidad y legitimidad del líder político. Esta conceptualización nos parece pertinente por las siguientes razones: (a) moviliza el sentido social, porque activa la energía ciudadana mediante el ejemplo y la coherencia; (b) incrementa la credibilidad, porque comunica a través de la verdad (los hechos mismos) y no desde la verosimilitud (las narraciones de los hechos); y (c) legitimidad, porque concede autoridad sin recurrir a la coacción ni a la amenaza de la misma.

Más allá de los cambios que, según el contexto social, político y cultural, pueda tener el storydoing político, consideramos conveniente destacar ciertos requisitos y propiedades básicos:

- Es en primera persona. Puede ser en singular (yo) o plural (nosotros), pero el líder siempre debe formar parte de la historia. El storyteller tiene que coincidir con el protagonista. Esto representa una diferencia sustancial con el storytelling, donde el líder podía relatar y capitalizar sucesos de terceros. Kerry Smith and Dan Hanover (2016) subrayan que el objetivo es personalizar la experiencia, apropiársela, sin perder de vista que hay que alcanzar una amplia audiencia.

- El mensaje debe reflejar acción, no pasividad. El líder político debe estar ejecutando la obra, no observándola. Esta centralidad es importante porque las imágenes que transmiten acción provocan una mayor resonancia afectiva en las personas (Goossens, 2003). La reputación de un político o una empresa va a estar determinada por la suma de sus acciones (Montague, 2018).

- El registro es visual. Las personas otorgamos mayor credibilidad a la imagen que al texto. El formato visual «crea la ilusión de que estamos mirando por la ventana al mundo real» (Gurri, Denny y Harms, 2010: 102). Cuando estamos frente a una fotografía nuestro sentido crítico se relaja y no nos preguntamos por su edición (la manipulación de los colores, por ejemplo), la selección del operador (cuál fue el criterio para elegir esta opción) y el encuadre (desde qué ángulo fue capturada y qué elementos quedaron fuera del campo visual). Además, las fotografías y los contenidos audiovisuales son sintetizadores de información: pueden almacenar una gran cantidad de significa- 
do en un breve lapso de tiempo. Esta cualidad es importante en un contexto limitado por la economía de la atención y la fragmentación discursiva.

- Representa una demanda social. El hecho comunicacional tiene que responder a una política pública, una expectativa o un sentimiento que exige la ciudadanía. El líder debe enlazar con el contexto en el que desarrolla su trabajo público. Es imperioso que conecte con las necesidades racionales y, en especial, los deseos emocionales de su entorno. Como asevera Papacharissi (2016), para formar un colectivo en la era digital, la dimensión afectiva de la política es clave. Cada acción debe encarnar un valor: honestidad, valentía, igualdad, humildad, solidaridad, perseverancia o dignidad, por citar algunos. De esta forma, el mensaje se transformará en mimético, las personas intentarán copiarlo y reproducirlo en sus vidas.

- Un adversario o un desafío explícito. Al igual que el storytelling, el storydoing posee un antagonista que, como indica Denning (2008), puede ser individual (Donald Trump, Nicolás Maduro o Marine Le Pen) o genérico («el populismo», «la pobreza», «la corrupción», «el imperialismo», etc.). Pero lo importante es que la historia siempre esté estructurada mediante un conflicto dicotómico entre buenos y malos que facilite la interpretación de la realidad.

- Simbología propia. La acción debe contar con una red de signos exclusiva, innovadora y diferenciadora. Los símbolos comprimen significados, activan las emociones y facilitan la comprensión (D’Adamo y García Beaudoux, 2016). En esta dimensión ingresan elementos como el escenario, la vestimenta, la gestualidad, la música, los iconos, las banderas, la cromática, etc.

- Secuencia y causalidad. La historia tiene que contar con un valor cardinal que la organice y una secuencia tripartita (introducción-nudo-desenlace) que le proporcione tensión narrativa. A su vez, para que la exposición denote coherencia, el tránsito de una fase a otra debe estar conducido por una lógica de causa y efecto. Por último, es imprescindible que exista una trama rectora que ordene los diferentes storydoing que genere el líder. Cada acción que se comunica debe estar conectada con su predecesora. Sin esta congruencia, la identidad del político perderá precisión.

- Atención completa. Las personas atraviesan con una atención continua parcial (Ellen, 2010) el actual ecosistema comunicacional. Esto quiere decir que enfrentan en una especie de «piloto automático» la inmensa cantidad de información que reciben diariamente. Sobrevuelan los incesantes estímulos que llegan desde los diferentes soportes y solo se detienen en aquellos mensajes que les impactan emocionalmente. Ahí es cuando pasan de la atención incompleta a la atención completa. Por sus características formales (visual y dinámico) y sustanciales (original y personal), el storydoing debería ser una de esas piezas comunicacionales que logra activar la concentración total.

- Memorable. Por último, un rasgo fundamental es su poder mnemotécnico. Un storydoing eficaz deja huellas en la mente del ciudadano. Es una experiencia que se recuerda fácilmente y, con el paso del tiempo, se transforma en información o guía para que las personas tomen decisiones en su vida, tales como el voto o la opinión sobre tal figura política. 


\section{Tipología del storydoing}

En este inciso se proponen diferentes tipos de storydoing. El objetivo es mostrar a través de líderes contemporáneos las variaciones que puede tener esta técnica narrativa. Si bien puede haber infinidad de usos, se presentan los más frecuentes.

- Íntimo. Frente a una sociedad que demanda coherencia entre las esferas pública y privada, los políticos abren las puertas de sus casas y, de un modo descontracturado, exhiben su privacidad. Un ejemplo nítido es el ex presidente uruguayo José Mujica, que brindaba entrevistas a periodistas de todo el mundo en su chacra de Rincón del Cerro. A través de este storydoing, transmitía un estilo de vida sencillo, humilde y modesto. Otro caso reciente es Mette Frederiksen, la Primera Ministra de Dinamarca, que subía vídeos a sus redes sociales que reflejaban cómo la máxima autoridad del país vivía la cuarentena en su hogar. Una reproducción que fue tendencia en el ciberespacio enseña a la líder socialdemócrata cantando clásicos del rock danés como Vågner I natten o Waking up in the night mientras cocina.

- Inaugural. El líder toma la iniciativa y desactiva temores o prejuicios colectivos sobre una temática en particular. El gobernador de Nueva York, Andrew Cuomo, cuando realizó el hisopado para saber si tenía Covid-19 en una conferencia de prensa es un ejemplo concreto. Así probó que era un proceso sencillo, sin peligros, y abrió el camino para que el resto de la ciudadanía accediera al examen. Yendo más atrás en el tiempo, se puede mencionar a Manuel Fraga y el embajador norteamericano, Biddle Duke, dándose un baño en Almería para demostrar que, a pesar de que había una bomba nuclear en el fondo del Mar Mediterráneo, se podía disfrutar de la playa sin riesgo alguno. Este storydoing se hizo específicamente para estimular el turismo, una de las industrias más importantes de España.

- Horizontal. Este storydoing aspira a crear empatía entre el líder y la ciudadanía a través de consumos, gustos o rutinas populares. El reto es visualizar que la presidenta vive como la mayoría, no como la minoría. Angela Merkel haciendo las compras en un supermercado como una alemana más; Barack Obama junto a su par ruso, Dmitri Medvédev, comiendo hamburguesas en Ray's Hell Burger; la primera ministra de Taiwán, Tsai Ing-wen, almorzando en el medio de la multitud en un mercado tradicional y el ex mandatario argentino, Mauricio Macri, armando el arbolito de navidad son ejemplos claros.

- Profesional. Aquí el líder demuestra que, a pesar de ocupar un cargo público importante, se hace un espacio para desarrollar su trabajo de toda la vida. De este modo, se intenta exponer que el poder no lo cambió y, al mismo tiempo, bloquear el estereotipo del político burócrata; en su lugar, se proyecta a una persona formada, capacitada y apta que solo por un tiempo está dedicándose a la función pública. El presidente argentino, Alberto Fernández, dando clases en la Facultad de Derecho de la Universidad de Buenos Aires es un ejemplo cabal de este tipo de storydoing. También el ex premier irlandés, Leo Varadkar, lo implementó cuando reactivó en plena pandemia del Covid-19 su licencia de médico para trabajar en un hospital de Dublín. Este gesto funcionó como disparador para que otros colegas de la salud retirados lo imitasen. 
- Atlético. Los políticos buscan instalar en la opinión pública que son fuertes, vitales y saludables a través de la práctica de algún deporte. Este es uno de los storydoing más recurrentes, por dos motivos: su fácil implementación y la popularidad que tiene la actividad física en la sociedad. El ex presidente de Bolivia, Evo Morales, jugando al fútbol por todo el país; el presidente español, Pedro Sánchez, corriendo por los jardines del Palacio de la Moncloa; el ex presidente peruano, Pedro Pablo Kuczynsky, junto a su gabinete, recibiendo sesiones de gimnasia en el Patio de Honor del Palacio de Gobierno son casos contundentes.

- Dinámico. Los gobernantes despliegan su agenda repleta de obligaciones y responsabilidades. A través de las redes sociales, se presentan activos, enérgicos y resolutivos durante todo el día. Van de un compromiso a otro sin pausas. Esto les aporta transparencia y sentido del deber. La primera ministra de Nueva Zelanda, Jacinda Ardern, es una gran exponente de esta clase de storydoing. Por medio de Facebook Live o Instagram Live, cuenta cómo es un día de la máxima autoridad. Desde el asiento trasero del automóvil oficial que la traslada de un sitio a otro se filma ella misma y relata la actividad que acaba de cumplir y cuál será la próxima. La ex formula presidencial norteamericana, Barack Obama y Joe Biden, también aplicó bastantes veces este storydoing. De hecho, hay un video que exhibe a los dos líderes, con camisa y corbata, trotando por la Casa Blanca y preparándose para afrontar una jornada recargada de trabajo.

- Ocio. La meta es demostrar que, al igual que cualquier ciudadano, la presidenta o el gobernador necesita descansar y desconectar de su trabajo. Sanna Marin, primera ministra de Finlandia, y Katrín Jakobsdóttir, su par de Islandia, emplean a menudo este storydoing cuando comunican desde sus redes sociales un descanso dominical, un viaje navideño, una escalada por algún sitio natural o una salida de bares con amigos. Es importante destacar que siempre escogen pueblos o comercios característicos de sus respectivos países para promocionar el turismo y la gastronomía locales. Esto es un indicio de que, aun en sus recesos, la política continúa.

- Yuxtaposición. Contrastar visualmente dos opciones políticas mediante hechos garantiza la memorización del contenido (Lilleker, 2019). Esto se debe a que quedan en evidencia las diferencias entre lo correcto y lo incorrecto. Lincoln Project, una plataforma de republicanos descontentos con la gestión de Donald Trump, hizo un spot de yuxtaposición donde alternaba imágenes de Joe Biden corriendo sin problemas con otras de Trump caminando con serias dificultades. Sobre el final del vídeo, se muestra al ex vicepresidente cogiendo un vaso con agua para hidratarse sin inconvenientes $y$, en el plano siguiente, se observa al $45^{\circ}$ presidente de los Estados Unidos endeble tratando de llevarse con las dos manos un vaso con agua a la boca. El cierre ofrece una placa que dice «Biden presidente. Él puede correr y beber agua». La contraposición es patente: el postulante demócrata al Despacho Oval es fuerte mientras que el republicano es débil.

Por último, es necesario enfatizar que el storydoing más eficaz es aquel que es compartido por el ciudadano. Es decir, que no se comunica desde los canales oficiales del líder sino que es producido y circulado a través de un vecino común. De esta manera, se evita la auto-propaganda e incrementa la credibilidad del mensaje. En la ciberdemocracia, es clave 
que los prosumidores sean protagonistas en el diseño de la imagen del político. El relato debe ser "escrito» entre la ciudadanía y el líder, con flujos comunicacionales de tipo ascendente (bubble up, de la sociedad hacia el dirigente) y descendente (top down, del dirigente hacia la sociedad). Si bien es posible que la pieza comunicacional no cumpla con los reglas técnicas y estéticas de un producto profesional, su carácter aficionado o artesanal le aportará espontaneidad y legitimidad al político.

\section{Conclusiones/Discusión}

El objetivo central de este trabajo era dotar de un marco teórico al storydoing político. Para cumplir dicha meta, primero, se efectuó una conceptualización del mismo. Teniendo como referencia la comunicación corporativa, se lo definió como un método narrativo que, a través de la visualización de hechos, puede activar voluntades y proporcionarle credibilidad y legitimidad al líder político. La diferencia con el storytelling es que, mientras éste se sustenta exclusivamente en palabras, el storydoing relata con hechos y palabras. Después, se mencionaron sus requisitos y características principales. Para que una pieza comunicacional sea considerada como storydoing debe ser activo, óptico, original, memorable, secuencial y capaz de activar la atención completa de las personas. Para cerrar esta aproximación teórica, se elaboró una tipología del storydoing, donde destacan los siguientes usos: íntimo, inicial, dinámico, atlético y profesional.

Se abren varios interrogantes para futuras investigaciones. Uno de ellos es vislumbrar cómo muta el storydoing según la red social escogida. ¿En qué medida se altera el formato y el contenido si se comunica desde Instagram, Facebook, Youtube y TikTok? Otra posibilidad sería descubrir la función que ocupa el texto en el storydoing político, si tiene una tarea retórica o de contextualización. En una época marcada por la autocomunicación de masas, también sería oportuno analizar cómo participa la sociedad en la construcción del storydoing. En otras palabras: observar si la ciudadanía se limita simplemente a replicar el contenido generado por los políticos o si, por el contrario, desarrolla un rol activo al ser la encargada de crear la fotografía o el vídeo e insertarlo en el ecosistema comunicacional. Por último, sería interesante vincular al storydoing con la escenificación del liderazgo, es decir, qué papel juegan las coordenadas espaciales y temporales en la historia que se intenta proyectar.

\section{Bibliografía}

BARAYBAR FERNÁNDEZ, Antonio y LUQUE DE MARCOS, Juan (2018). «Nuevas tendencias en la construcción de marcas: una aproximación al storydoing». Prisma Social, (23), 435-458.

BOYD, Danah (2008). "Can social network sites enable political action?». In: A. Fine, M. Sifry, A. Rasiej, and J. Levy (Eds.). Rebooting America, 112-116. Mountain View: Creative Commons.

BROOKS, Arthur (2019). Love your enemies. New York: Broadside Books.

CASTELLS, Manuel (2011). Poder y comunicación. Buenos Aires: Siglo XXI editores.

CHAMORRO-PREMUZIC, Thomas (2014). «How the web distorts reality and impairs our judgement skills». The Guardian, 13 de mayo. Recuperado de https://bit.ly/3j4bcbG 
DENNING, Stephen (2008). "Storytelling in civic and political leadership». Encyclopedia of Political and Civic Leadership. Recuperado de http://www.stevedenning.com/Documents/ StorytellingForPolitical\&CivicLeadersNov25-08.pdf

D'ADAMO, Orlando y GARCÍA BEAUDOUX, Virginia (2016). «Comunicación Política: narración de historias, construcción de relatos políticos y persuasión». Comunicación y Hombre, (12), 33-36.

DAHLGREN, Peter (2005). «The Internet, public spheres, and political communication: Dispersion and deliberation». Political Communication, 22(2), 147-162. DOI: 10.1080/10584600590933160

ELLEN, Rose (2010). «Continuous partial attention: Reconsidering the role of online learning in the age of interruption». Educational Technology, 50(4), 41-46.

FRIEDMAN, Thomas (2006). «The interruption age». The New York Times, 5 de julio. Recuperado de https://nyti.ms/31lrxD1

GERODIMOS, Roman (2019). "The interdisciplinary roots and digital branches of visual political communication research». In: Veneti, Anastasia, Jackson, Daniel y Lileker, Darren G. (Eds.). Visual Political Communication, 53-75. Basingstoke: Palgrave Macmillan.

GIL CALVO, Enrique (2018). Comunicación política. Caja de herramientas. Madrid: Catarata.

GOLDHABER, Michael (1997). «The attention economy and the net». First Monday, 2(4). Recuperado de https://firstmonday.org/article/view/519/440

GOOSSENS, Cees (2003). «Visual persuasion: Mental imagery processing and emotional experiences». In: Linda M. Scott y Rajeev Batra (Eds.). Persuasive imagery: A consumer response perspective, 129-139. London: Lawrence Erlbaum.

GURRI, Martin, DENNY, Craig y HARMS, Aaron (2010). “Our visual persuasion Gap». The US Army War College Quarterly: Parameters, 40(1). Recuperado de https://press.armywarcollege.edu/ parameters/vol40/iss1/7I

GUTIÉRREZ-RUBÍ, Antoni (2009). Micropolítica. Ideas para cambiar la comunicación política. Recuperado de https://n9.cl/357d

GUTIÉRREZ-RUBÍ, Antoni (2019). Gestionar las emociones políticas. Barcelona: Gedisa.

HAIDT, Jonathan (2019). La mente de los justos. Barcelona: Deusto.

HAND, Martin (2012). Ubiquitous photography. Cambridge: Polity Press.

LANHAM, Richard (2007). The economics of attention. Chicago: The University of Chicago press.

LILLEKER, Darren (2019). «The power of visual political communication: Pictorial politics through the lens of communication psychology». In Veneti, Anastasia, Jackson, Daniel y Lileker, Darren G. (Eds.). Visual Political Communication, 37-53. Basingstoke: Palgrave Macmillan.

LILLEKER, Darren y LIEFBROER, Miriam (2018). "SSearching for something to believe in": Voter uncertainty in a post-truth environment». International Journal of Media \& Cultural Politics, 14(3), 351-364.

LUNTZ, Frank (2011). La palabra es poder. Madrid: Esfera libros.

MCADAMS, Dan (2006). The redemptive self. Stories Americans live by. New York: Oxford University Press.

MESSARIS, Paul (2019). «The digital transformation of visual politics». In Veneti, Anastasia, Jackson, Daniel y Lileker, Darren G. (Eds.). Visual Political Communication, 17-37. Basingstoke: Palgrave Macmillan.

MONTAGUE, Ty (2018). True story. How to combine story and action to transform your business. Boston: Harvard Business Review Press. 
NASKAR, Abhijit (2019). The constitution of the united peoples of earth. Autoedición. New York: Routledge. PAPACHARISSI,Zizi (2016). «Affective publics and structures of storytelling:sentiment, events and mediality». Information, Communication \& Society, 19(3), 307-324. DOI: 10.1080/1369118X.2015.1109697

PERLOFF, Richard (2018). The dynamics of political communication. Media and politics in a digital age. New York and London: Reutledge.

POPKIN, Samuel (1994). The reasoning voter: Communication and persuasion in presidential campaigns. Chicago, IL: University of Chicago Press.

RITZER, George y JURGENSON, Nathan (2010). «Production, consumption, prosumption. The nature of capitalism in the age of the digital "prosumer"». Journal of Consumer Culture, 10(1), 13-36. DOI: $10.1177 / 1469540509354673$

SALMON, Christian (2008). «"Hemos pasado de la opinión pública a la emoción pública”, entrevista de Renée Kantor». Foreign Policy Edición Española, (27), 64-68.

SALMON, Christian (2019). La era del enfrentamiento. Barcelona: Península.

SMITH, Kerry y HANOVER, Dan (2016). Experiental marketing. Secrets, strategies, and success stories from the world's greatest brands. New Jersey: John Wiley \& Sons.

VALLANCE, Charles (2016). "Storytelling is dead. Long live sory doing». Campaign, 22 de agosto. Recuperado de https://bit.ly/32nG00t

WEBER, Larry (2019). Authentic marketing. New Jersey: John Wiley \& Sons. 